\title{
Anne Steinemann
}

Professor of Civil Engineering

Chair of Sustainable Cities

Department of Infrastructure Engineering

Melbourne School of Engineering

The University of Melbourne

Melbourne Victoria 3010 Australia

Adjunct Professor

College of Science, Technology and Engineering

James Cook University

Townsville Queensland 4811 Australia

Research Associate

Climate, Atmospheric Sciences, and Physical Oceanography

Scripps Institution of Oceanography

University of California, San Diego

La Jolla, CA 92093 USA

email: anne.steinemann@unimelb.edu.au

phone: +610383445001 


\title{
Exposures and Effects from Fragranced Consumer Products in Sweden
}

\begin{abstract}
Fragranced consumer products—-such as cleaning supplies, perfume, and air fresheners - have been associated with indoor air pollutants and adverse human health effects. Through a nationally representative population-based survey, this study investigates sources and risks associated with exposure to fragranced consumer products in Sweden. It examines the frequency and types of fragranced product use, associated health effects, exposure situations, knowledge of product emissions, and preferences for fragrance-free policies and indoor environments. Data were collected in July 2017 using an online survey of adults $(n=1,100)$, representative of age, gender, and region in Sweden. Across the Swedish population, 33.1\% report health problems, such as respiratory difficulties (20.0\%), migraine headaches $(16.1 \%)$, and asthma attacks (5.5\%), when exposed to fragranced products. Of these reports, $24.2 \%$ could be considered potentially disabling. While $98.5 \%$ use fragranced products at least once a week, $70.9 \%$ were unaware that fragranced products, even ones called green and organic, can emit potentially hazardous air pollutants. Importantly, $6.7 \%$ of the population lost workdays or a job, in the past year, due to exposure to fragranced products in the workplace. Also, $18.1 \%$ enter and then leave a business as quickly as possible due to air fresheners or a fragranced product. A strong majority of the population would prefer that workplaces, health care facilities and professionals, airplanes, and hotels were fragrance-free rather than fragranced. Results from this study provide new and important evidence that exposure to fragranced consumer products is pervasive in Sweden, that these exposures are associated with adverse health and societal effects, and that reducing exposures such as through fragrance-free policies can provide benefits to air quality and public health.
\end{abstract}

Keywords: fragranced consumer product, fragrance, fragrance-free policy, indoor air quality 


\section{Introduction}

Swedish society is filled with fragranced consumer products. Fragranced consumer products (or fragranced products) are chemically formulated products with the addition of a fragrance, aroma, or scent (Steinemann 2015). Common products include air fresheners, laundry detergents, cleaning supplies, personal care products, household items, soaps, hand sanitizers, baby products, and cosmetics_ — among hundreds of products that are used by individuals, industries, and institutions every day.

Fragranced consumer products contain and emit complex mixtures of chemicals, such as the volatile organic compounds (VOCs) limonene, alpha-pinene, beta-pinene, ethanol, acetone, and acetaldehyde (Steinemann 2015), which contribute to personal exposure and indoor air pollution. In addition, fragranced product emissions of terpenes (e.g., limonene) react with ozone to generate secondary pollutants such as formaldehyde (e.g., Carslaw 2013; Nazaroff and Weschler 2004).

Previous studies of fragranced product emissions found that relatively few ingredients were disclosed to the public (e.g., Uhde and Schultz 2015; Steinemann et al. 2011; Steinemann 2015). For instance, Steinemann (2015) found over 150 different VOCs emitted from 37 fragranced consumer products in the US, with 42 VOCs classified as toxic or hazardous under US federal laws. Emissions of hazardous air pollutants from so-called green, organic, or natural fragranced products were not significantly different from regular fragranced products. However, fewer than $3 \%$ of over 550 collective ingredients were disclosed to the public on the product labels, material safety data sheets, or websites. Further, over two-thirds of the fragranced consumer products, other than cosmetics, did not disclose that the product contained a fragrance. In the European Union, the cosmetics directive requires listing of any of 26 fragrance allergens present above $0.001 \%$ in leave-on products and $0.01 \%$ in rinse-off 
products (EC 2009). However, currently no law in Sweden, or in any other country (to best knowledge), requires complete disclosure of all ingredients in fragranced consumer products (Steinemann 2009; Lunny et al. 2017).

Fragranced consumer products have been associated with a range of adverse health effects including migraine headaches (Steinemann 2016, 2017, 2018; Kelman 2004), asthma and asthmatic reactions (Weinberg et al. 2017; Steinemann 2016, 2017, 2018), breathing difficulties (Caress and Steinemann 2009), mucosal symptoms (Elberling et al. 2005; Millqvist and Löwhagen, 1996), and contact dermatitis (Matura et al. 2005; Johansen 2003; Rastogi et al. 2007). In three other studies parallel to this one, nationally representative surveys in the USA (Steinemann 2016), Australia (Steinemann 2017) and the UK (Steinemann 2018) found that $34.7 \%, 33.0 \%$, and $28.7 \%$ of the population (respectively) reported one or more type of adverse health effects from exposure to fragranced products.

In Sweden, previous regional studies determined the prevalence of intolerance to odours from certain fragranced products. In Skövde, Johansson et al. (2005) found a prevalence of 33.0\% self-reported general odour intolerance among adults aged 20 and over $(n=1,387)$, as determined by "Are you bothered by strong odours (e.g., perfume, cleaning agents or flower scents)?" Also in Skövde, using the same criterion, Andersson et al. (2008) found a prevalence of $15.6 \%$ self-reported odour intolerance among teenagers aged 13-19 ( $n=326)$. In Västerbotten, Palmquist et al. (2014) found a prevalence of $12.2 \%$ of odorous/pungent chemical intolerance among respondents aged 18-79 $(n=3,406)$, as determined by "Are you getting symptoms from odorous/pungent chemicals (not limited to certain buildings), such as perfumes and cleaning agents?"

This article reports results from a nationally representative study of Sweden to investigate the sources of emissions and the health and societal effects from fragranced consumer products. 
It complements recent national studies in the US, Australia, and the UK, and supports previous regional studies in Sweden, by providing new data on the extent and types of problems, and opportunities for solutions.

\section{Methods}

Using a national random sample representative of age, gender, and region $(n=1,100$; confidence limit $=95 \%$, confidence interval $=3 \%$ ), an on-line survey was conducted of the adult population (ages 18-65) in Sweden. The survey instrument was developed and tested over a three-year period, and used in three other national prevalence studies (Steinemann 2016, 2017, 2018).

The survey was run in the official national language of Swedish. The process of survey translation and implementation was performed by Survey Sampling International (SSI), a global survey research company and online panel provider. The survey was translated from English into Swedish by a professional linguist and native speaker based in Sweden, and proofread by another professional linguist and native speaker based in the UK for balance in the translation process. The survey was then piloted with 100 individuals before full implementation in July 2017.

The survey drew upon participants from a large web-based panel in Sweden (approximately 60,000 people), developed and held by SSI, using multi-source samples to achieve a panel blend that reflects the heterogeneity of the study population. [See SSI (2018), and Electronic Supplementary Materials "SSI Methodologies" and "Survey Methodology."] To minimize risk of bias, recruitment followed a three-step randomization process to identify potential participants [See SSI (2018), and Electronic Supplementary Materials "SSI Methodologies" 
and "Survey Methodology."] The survey completion rate was 92\%, and all responses were anonymous. The research study received ethics approval from the University of Melbourne. Demographic information is provided in Table 1. Survey methods follow procedures reported in Steinemann $(2016,2017,2018)$. Details on the survey methodology, including the checklist for reporting results of internet e-surveys (CHERRIES, Eysenbach 2004), are provided as Electronic Supplementary Material ("Survey Methodology").

Survey questions investigated the following areas: use and exposure to fragranced products; health effects related to exposures to fragranced consumer products; specific exposure situations; effects of fragranced product exposure in the workplace and in society; awareness of fragranced product ingredients and labelling; preferences for fragrance-free environments and policies; and demographic information.

Fragranced products were categorized as follows: (a) air fresheners and deodorizers (e.g., sprays, solids, oils, disks); (b) personal care products (e.g., soaps, hand sanitizer, lotions, deodorant, sunscreen, shampoos); (c) cleaning supplies (e.g., all-purpose cleaners, disinfectants, and dishwashing soap); (d) laundry products (e.g., detergents, fabric softeners, dryer sheets); (e) household products (e.g., scented candles, toilet paper, trash bags, baby products); (f) fragrance (e.g., perfume, cologne, after-shave); and (g) other.

Health effects were categorized as follows: (a) migraine headaches; (b) asthma attacks; (c) neurological problems (e.g., dizziness, seizures, head pain, fainting, loss of coordination); (d) respiratory problems (e.g., difficulty breathing, coughing, shortness of breath); (e) skin problems (e.g., rashes, hives, red skin, tingling skin, dermatitis); (f) cognitive problems (e.g., difficulties thinking, concentrating, or remembering); (g) mucosal symptoms (e.g., watery or red eyes, nasal congestion, sneezing); (h) immune system problems (e.g., swollen lymph glands, fever, fatigue); (i) gastrointestinal problems (e.g., nausea, bloating, cramping, 
diarrhea); (j) cardiovascular problems (e.g., fast or irregular heartbeat, jitteriness, chest discomfort); (k) musculoskeletal problems (e.g., muscle or joint pain, cramps, weakness); (j) other.

Specific exposure situations were investigated: air fresheners or deodorizers used in public restrooms and other environments, scented laundry products emitted from a dryer vent, being in a room after it was cleaned with scented cleaning products, being near someone wearing a fragranced product, entering a business with the scent of air freshener or some fragranced product, fragranced soap used in public restrooms, and ability to access environments that used fragranced products.

In addition, questions investigated the loss of workdays or a job in the past year due to fragranced product exposure in the workplace, awareness of fragranced product emissions and ingredient disclosure, and preferences for fragrance-free environments (i.e., workplaces, health care facilities and health care professionals, airplanes, and hotels).

\section{Results}

Main findings from the survey are summarized in this section, and complete data on responses to survey questions are provided as Electronic Supplementary Material ("Survey Data").

Fragranced product use:

Among the Swedish population, $98.5 \%$ are exposed to fragranced products at least once a week from their own use: $54.4 \%$ air fresheners and deodorizers; $90.2 \%$ personal care 
products; $79.7 \%$ cleaning supplies; $76.4 \%$ laundry products; $68.0 \%$ household products; $63.3 \%$ fragrance; $3.1 \%$ other.

In addition, $93.3 \%$ are exposed to fragranced products at least once a week from others' use: 45.2\% air fresheners and deodorizers; $66.0 \%$ personal care products; $43.9 \%$ cleaning supplies; $45.6 \%$ laundry products; $35.3 \%$ household products; $76.0 \%$ fragrance; $2.5 \%$ other.

Collectively, $99.5 \%$ are exposed to fragranced products at least once a week from their own use, others' use, or both.

Health effects:

Overall, $33.1 \%$ of the population reported one or more types of adverse health effects from exposure to one or more types of fragranced products. The most common types of adverse health effects were as follows: $20.0 \%$ respiratory problems; $13.5 \%$ mucosal symptoms; $16.1 \%$ migraine headaches; $6.5 \%$ skin problems; $5.5 \%$ asthma attacks; $5.0 \%$ neurological problems; $4.5 \%$ cognitive problems; $3.5 \%$ gastrointestinal problems; $2.1 \%$ cardiovascular problems; $1.5 \%$ immune system problems; $1.5 \%$ musculoskeletal problems; and $2.2 \%$ other. (See Table 2.)

Of the $33.1 \%$ of the population reporting adverse health effects, $64.0 \%$ are female and $36.0 \%$ are male. Thus, proportionately more females report adverse health effects than males, relative to the general population (female $49.5 \%$, male 50.5\%). Among all gender and age group classifications, proportionately more females aged 45-54 report adverse health effects $(16.5 \%)$ relative to the general population $(12.1 \%)$. (See Table 1.) 
Specific fragranced products and exposure situations that trigger adverse health effects include the following (see Table 3):

Air fresheners and deodorizers: $17.3 \%$ reported health problems when exposed to air fresheners or deodorizers. This compares to studies of the USA, Australia, and the UK (Steinemann 2016, 2017, 2018) that found 20.4\%, 16.4\%, and $15.5 \%$ (respectively) reported health problems when exposed to air fresheners or deodorizers $(\chi 2=(1, \mathrm{~N}=4435)=8.937$, $\mathrm{p}=0.0301)$.

Scented laundry products: $5.6 \%$ reported health problems from the scent of laundry products coming from a dryer vent. This compares to studies of the USA, Australia, and the UK (Steinemann 2016, 2017, 2018) that found $12.5 \%, 6.1 \%$, and $6.0 \%$ (respectively) reported health problems from the scent of laundry products coming from a dryer vent $(\chi 2=(1, \mathrm{~N}=$ $4435)=48.295, \mathrm{p}<0.0001)$.

Fragranced cleaning products: $13.8 \%$ reported health problems from being in a room after it has been cleaned with scented products. This compares to studies of the USA, Australia, and the UK (Steinemann 2016, 2017, 2018) that found 19.7\%, 15.3\%, and 14.0\% (respectively) reported health problems from being in a room after it has been cleaned with scented products. $(\chi 2=(1, \mathrm{~N}=4435)=16.167, \mathrm{p}=0.0010)$

Proximity to fragranced person: $23.5 \%$ reported health problems from being near someone who is wearing a fragranced product. This compares to studies of the USA, Australia, and the UK (Steinemann 2016, 2017, 2018) that found 23.6\%, 19.4\%, and 13.7\% (respectively) 
reported health problems from being near someone who is wearing a fragranced product. $\left(\chi^{2}\right.$ $=(1, \mathrm{~N}=4435)=35.822, \mathrm{p}<0.0001)$.

Overall, adverse health effects from fragranced product exposures: $33.1 \%$ reported one or more types of health problems from being exposed to one or more types of fragranced products. This compares to studies of the USA, Australia, and the UK (Steinemann 2016, 2017,2018 ) that found $34.7 \%, 33.0 \%$, and $27.8 \%$ (respectively) reported health problems from exposure to fragranced products $\left(\chi^{2}=(1, \mathrm{~N}=4435)=9.166, \mathrm{p}=0.0271\right)$. Chi-squared analyses indicate that a significant difference $(\mathrm{p}<0.05)$ exists among the four countries for each of the four types of fragranced products and exposure situations above, as well as the overall percentages of the national populations adversely affected by fragranced products.

Severity of the health problems resulting from exposure to one or more types of fragranced products was investigated, using language from Swedish Discrimination Act (DA 2008) to determine disability: "Do any of these health problems cause any physical, psychological or intellectual limitations on your functional ability?" Of those adversely affected by fragranced products, $24.2 \%$ answered yes, indicating that the severity of effects from fragranced product exposure was potentially disabling.

Ingredient disclosure and product claims:

Across the population, $73.4 \%$ were not aware that fragrance chemicals do not need to be fully disclosed on the product label or material safety data sheet. Also, 58.4\% were not aware that fragranced products typically emit hazardous air pollutants such as formaldehyde, and $70.9 \%$ were not aware that even so-called natural, green, and organic fragranced products typically emit hazardous air pollutants. Yet 50.9\% would not still use a fragranced product if they knew it emitted hazardous air pollutants. 
Societal and workplace effects:

The use of fragranced products by others can create barriers and adverse consequences in society. Across the population, $12.0 \%$ are unable or reluctant to use the restrooms in a public place because of the presence of an air freshener, deodorizer, or scented product. Also, $6.7 \%$ are unable or reluctant to wash their hands with soap in a public place because they know or suspect that the soap is fragranced. Further, $18.1 \%$ reported that if they enter a business, and smell air fresheners or some fragranced product, they want to leave as quickly as possible. More broadly, $12.6 \%$ have been prevented from going to some place because they would be exposed to a fragranced product that would make them sick. Significantly, $6.7 \%$ of the population reported that exposure to fragranced products in their work environment, in the past year, has caused them to become sick, lose workdays, or lose a job.

Fragrance-free policies and scent-free indoor environments receive strong support (Table 4). Of the population surveyed, $50.7 \%$ would be supportive of a fragrance-free policy in the workplace (compared to $16.4 \%$ that would not). Thus, over 3 times as many would support a fragrance-free policy in the workplace than not. Also, $64.1 \%$ would prefer that health care facilities and health care professionals be fragrance-free (compared to $14.0 \%$ that would not). Thus, over 4 times as many would prefer health care facilities and health care professionals were fragrance-free than not.

Scenting indoor environments may detract rather than attract customers. If given a choice between flying on an airplane that pumped scented air throughout the passenger cabin, or did not pump scented air throughout the passenger cabin, $80.2 \%$ would choose an airplane without scented air (compared to 6.0\% with scented air). Thus, over 13 times more passengers would prefer an airplane without scented air than with scented air. Similarly, if given a choice between staying in a hotel with fragranced air, or without fragranced air, $77.7 \%$ would choose a hotel without fragranced air 
(compared to $9.8 \%$ with fragranced air). Thus, over 7 times more hotel guests would choose a hotel without fragranced air than with fragranced air.

Strengths of the study include the following: (a) the sample population is statistically representative of age, gender, and region in Sweden (1,100 respondents, 95\% confidence level, $3 \%$ confidence interval); (b) the 1,100 respondents were randomly recruited from a large web-based panel (approximately 60,000 people in Sweden) developed from multiple sources to reflect characteristics of the study population; (c) the survey questions paralleled three nationally representative studies previously conducted in other countries (Steinemann 2016, 2017, 2018); and (d) the survey was run in the official national language of Swedish.

Limitations include the following: (a) all possible products and health effects were not included, although the low percentages for responses in the "other" category indicates the survey captured the primary products and effects, (b) data were based on self-reports, although a standard method for survey research, it was not possible to measure emissions and effects directly for each respondent, (c) the cross-sectional design of the study, which useful for determining prevalence, is limited in the ability to determine temporal relationships and trends, and (d) the survey was focused on adults ages 18-65, which excludes data on effects of fragranced consumer products on children and the elderly.

\section{Conclusions}

Results from this study provide compelling evidence that fragranced consumer products are associated with a range of adverse health and societal effects across the Swedish population. Over one-third of the population in Sweden report one or more types of health problems when exposed to one or more types of common fragranced consumer products. Further, over 
one-fourth of those affected individuals report that the health problems can be potentially disabling.

Many problematic exposures are involuntary: $12.0 \%$ of the population are unable or reluctant to use restrooms in public places because of air fresheners or deodorizers, $6.7 \%$ unable or reluctant to wash their hands with soap in public places because of fragranced soap, $12.6 \%$ unable to go someplace because of the presence of a fragranced product, and $18.1 \%$ would enter but then leave a business as quickly as possible if they smell fragranced products.

Importantly, $6.7 \%$ have lost workdays or a job, in the past year, due to fragranced product exposures in the workplace. A strong majority would prefer fragrance-free rather than fragranced environments, and would support fragrance-free policies in workplaces.

Results from this study, together with results from the US, Australia, and the UK, have the global implication that common fragranced products can be considered a pervasive public health problem. While research continues to investigate which chemicals and mixtures of chemicals are associated with adverse health effects, an important precaution would be to reduce exposure to fragranced consumer products.

\section{Acknowledgements}

I thank Amy Davis for her valuable assistance. I also thank the staff of Survey Sampling International for their superb work. I declare that I have no actual or potential competing financial interests. 


\section{References}

Andersson L, Johansson A, Millqvist E, Nordin S, Bende M. 2008. Prevalence and risk factors for chemical sensitivity and sensory hyperreactivity in teenagers. International Journal of Hygiene and Environmental Health 211(5-6):690-7

Caress SM, Steinemann AC. 2009. Prevalence of Fragrance Sensitivity in the American Population. Journal of Environmental Health 71(7):46-50.

Carslaw N 2013. A mechanistic study of limonene oxidation products and pathways following cleaning activities. Atmospheric Environment 80:507-513.

(DA) Discrimination Act (Diskrimineringslagen 2008:567), Section 5:4.

Definition of disability, Section 5:4.

https://www.riksdagen.se/sv/dokument-lagar/dokument/svenskforfattningssamling/diskrimineringslag-2008567_sfs-2008-567

Elberling J, Linneberg A, Dirksen A, Johansen JD, Frølund L, Madsen F, Nielsen NH, Mosbech H 2005. Mucosal symptoms elicited by fragrance products in a population-based sample in relation to atopy and bronchial hyper-reactivity. Clinical and Experimental Allergy $35(1): 75-81$.

Eysenbach G 2004. Improving the Quality of Web Surveys: The Checklist for Reporting Results of Internet E-Surveys (CHERRIES). Journal of Medical Internet Research 6(3):e34. 
(EC) European Commission 2009. Regulation (EC) No 1223/2009 of the European

Parliament and of the Council of 30 November 2009 on Cosmetic Products.

Johansen JD 2003. Fragrance contact allergy: a clinical review. American Journal of Clinical Dermatology 4(11):789-98.

Johansson Å, Brämerson A, Millqvist E, Nordin S, Bende M 2005. Prevalence and risk factors for self-reported odour intolerance: the Skövde population-based study. International Archives of Occupational and Environmental Health 78:559-564.

Kelman L 2004. Osmophobia and taste abnormality in migraineurs: a tertiary care study. Headache 44(10):1019-23.

Lunny S, Nelson R, Steinemann A. 2017. Something in the Air but not on the Label: A Call for Increased Regulatory Ingredient Disclosure for Fragranced Consumer Products. University of New South Wales Law Journal 40(4):1366-1391.

Matura M, Sköld M, Börje A, Andersen KE, Bruze M, Frosch P, Goossens A, Johansen JD, Svedman C, White IR, Karlberg AT. 2005. Selected oxidized fragrance terpenes are common contact allergens. Contact Dermatitis 52(6):320-8.

Millqvist E, Löwhagen O 1996. Placebo-controlled challenges with perfume in patients with asthma-like symptoms. Allergy 51(6):434-9.

Nazaroff WW, Weschler CJ 2004. Cleaning products and air fresheners: exposure to primary and secondary air pollutants. Atmospheric Environment 38(18):2841-65. 
Palmquist E, Claeson AS, Neely G, Stenberg B, Nordin S. 2014. Overlap in prevalence between various types of environmental intolerance. International Journal of Hygiene and Environmental Health. 217(4-5):427-34.

Rastogi SC, Johansen JD, Bossi R 2007. Selected important fragrance sensitizers in perfumes—current exposures. Contact Dermatitis 56(4):201-4.

SSI (Survey Sampling International) 2018 Dynamix Sampling Approach. Available from: https://www.surveysampling.com/technology/ssi-dynamix/ (accessed February 22, 2018)

Steinemann A 2018. Fragranced Consumer Products: Sources of Emissions, Exposures, and Health Effects in the United Kingdom. Air Quality, Atmosphere, and Health (in press)

Steinemann A 2017. Health and Societal Effects from Fragranced Consumer Products. Preventive Medicine Reports 5:45-47.

Steinemann A 2016. Fragranced Consumer Products: Exposures and Effects from Emissions. Air Quality, Atmosphere, and Health 9(8):861-866.

Steinemann A 2015. Volatile emissions from common consumer products. Air Quality, Atmosphere \& Health 8(3): 273-281.

Steinemann AC 2009. Fragranced consumer products and undisclosed ingredients. Environmental Impact Assess Review 29(1):32-8. 
Steinemann AC, MacGregor IC, Gordon SM, Gallagher LG, Davis AL, Ribeiro DS, Wallace LA 2011. Fragranced consumer products: chemicals emitted, ingredients unlisted Environmental Impact Assessment Review 31(3):328-33.

Uhde E, Schulz N 2015. Impact of room fragrance products on indoor air quality. Atmospheric Environment 106:492-502.

Weinberg JL, Flattery J, Harrison R 2017. Fragrances and work-related asthma-California surveillance data, 1993-2012. Journal of Asthma 54 (10):1041-1050. 
Table 1: Demographic information.

\begin{tabular}{|c|c|c|c|c|}
\hline \multirow[b]{2}{*}{ Age } & \multicolumn{2}{|c|}{$\begin{array}{l}\text { Respondents with } \\
\text { Health Problems } \\
\text { from Exposure to } \\
\text { Fragranced Products }\end{array}$} & \multicolumn{2}{|c|}{ Population Sample } \\
\hline & $\begin{array}{l}\text { Male } \\
(n, \%)\end{array}$ & $\begin{array}{c}\text { Female } \\
(n, \%)\end{array}$ & $\begin{array}{l}\text { Male } \\
(n, \%)\end{array}$ & $\begin{array}{c}\text { Female } \\
(n, \%)\end{array}$ \\
\hline $18-24$ & $\begin{array}{c}19 \\
21.3 \%\end{array}$ & $\begin{array}{c}20 \\
29.4 \%\end{array}$ & $\begin{array}{c}89 \\
8.1 \%\end{array}$ & $\begin{array}{c}68 \\
6.2 \%\end{array}$ \\
\hline $25-34$ & $\begin{array}{c}25 \\
22.7 \%\end{array}$ & $\begin{array}{c}51 \\
44.0 \%\end{array}$ & $\begin{array}{c}110 \\
10.0 \%\end{array}$ & $\begin{array}{c}116 \\
10.5 \%\end{array}$ \\
\hline $35-44$ & $\begin{array}{c}33 \\
24.6 \%\end{array}$ & $\begin{array}{c}48 \\
42.9 \%\end{array}$ & $\begin{array}{c}134 \\
12.2 \%\end{array}$ & $\begin{array}{c}112 \\
10.2 \%\end{array}$ \\
\hline $45-54$ & $\begin{array}{c}26 \\
23 . \%\end{array}$ & $\begin{array}{c}60 \\
45.1 \%\end{array}$ & $\begin{array}{c}113 \\
10.3 \%\end{array}$ & $\begin{array}{c}133 \\
12.1 \%\end{array}$ \\
\hline $55-65$ & $\begin{array}{c}28 \\
25.5 \%\end{array}$ & $\begin{array}{c}54 \\
47.0 \%\end{array}$ & $\begin{array}{c}110 \\
10.0 \%\end{array}$ & $\begin{array}{c}115 \\
10.5 \%\end{array}$ \\
\hline Total & $\begin{array}{c}131 \\
23.6 \%\end{array}$ & $\begin{array}{c}233 \\
42.8 \%\end{array}$ & $\begin{array}{c}556 \\
50.5 \%\end{array}$ & $\begin{array}{c}544 \\
49.5 \%\end{array}$ \\
\hline
\end{tabular}


Table 2: Frequency and types of adverse health effects reported from exposure to fragranced consumer products.

\begin{tabular}{|c|c|}
\hline Health Problems & $\begin{array}{c}\text { Frequency } \\
(\mathrm{n}) \\
\text { (\% of general population) }\end{array}$ \\
\hline \multirow[t]{2}{*}{ Total } & 364 \\
\hline & $33.1 \%$ \\
\hline \multicolumn{2}{|l|}{ Type of Health Problem } \\
\hline \multirow[t]{2}{*}{ Migraine headaches } & 177 \\
\hline & $16.1 \%$ \\
\hline \multirow[t]{2}{*}{ Asthma attacks } & 61 \\
\hline & $5.5 \%$ \\
\hline \multirow[t]{2}{*}{ Neurological problems } & 55 \\
\hline & $5.0 \%$ \\
\hline \multirow[t]{2}{*}{ Respiratory problems } & 220 \\
\hline & $20.0 \%$ \\
\hline \multirow[t]{2}{*}{ Skin problems } & 71 \\
\hline & $6.5 \%$ \\
\hline \multirow[t]{2}{*}{ Cognitive problems } & 50 \\
\hline & $4.5 \%$ \\
\hline \multirow[t]{2}{*}{ Mucosal symptoms } & 149 \\
\hline & $13.5 \%$ \\
\hline \multirow[t]{2}{*}{ Immune system problems } & 16 \\
\hline & $1.5 \%$ \\
\hline \multirow[t]{2}{*}{ Gastrointestinal problems } & 39 \\
\hline & $3.5 \%$ \\
\hline \multirow[t]{2}{*}{ Cardiovascular problems } & 23 \\
\hline & $2.1 \%$ \\
\hline \multirow[t]{2}{*}{ Musculoskeletal problems } & 17 \\
\hline & $1.5 \%$ \\
\hline \multirow[t]{2}{*}{ Other } & 24 \\
\hline & $2.2 \%$ \\
\hline
\end{tabular}


Table 3: Frequency and types of health problems from exposure to four types of fragranced consumer products. $\mathrm{AF}=$ air fresheners or deodorizers, $\mathrm{LP}=$ scent of laundry products coming from a dryer vent, $\mathrm{CP}=$ being in a room after it has been cleaned with scented products, FP = being near someone wearing a fragranced product. (\% of general population)

\begin{tabular}{|l|c|c|c|c|}
\hline & Air Fresheners (AF) & $\begin{array}{c}\text { Laundry Products } \\
\text { (LP) }\end{array}$ & $\begin{array}{c}\text { Cleaning Products } \\
\text { (CP) }\end{array}$ & $\begin{array}{c}\text { Fragranced Person } \\
\text { (FP) }\end{array}$ \\
\hline Health Problems & 190 & 62 & 152 & 259 \\
(n) & $17.30 \%$ & $5.60 \%$ & $13.80 \%$ & $23.50 \%$ \\
Type of Heaneral population) & & & & \\
Migraines & & & & \\
Asthma attacks & & & & \\
Neurological & $6.7 \%$ & $1.6 \%$ & $6.2 \%$ & $11.5 \%$ \\
Respiratory & $3.3 \%$ & $1.1 \%$ & $1.9 \%$ & $3.3 \%$ \\
Cognitive & $2.9 \%$ & $0.5 \%$ & $1.5 \%$ & $2.5 \%$ \\
Mucosal & $9.6 \%$ & $1.7 \%$ & $7.4 \%$ & $14.0 \%$ \\
Immune system & $3.1 \%$ & $1.8 \%$ & $1.4 \%$ & $1.6 \%$ \\
Gastrointestinal & $1.9 \%$ & $0.6 \%$ & $1.6 \%$ & $2.6 \%$ \\
Cardiovascular & $6.8 \%$ & $1.5 \%$ & $5.9 \%$ & $7.8 \%$ \\
Musculoskeletal & $0.6 \%$ & $0.4 \%$ & $0.4 \%$ & $0.4 \%$ \\
Other & $1.3 \%$ & $0.3 \%$ & $1.0 \%$ & $2.3 \%$ \\
\hline
\end{tabular}


Table 4: Percentage of individuals who prefer fragrance-free environments

\begin{tabular}{|l|l|l|l|l|}
\hline & Yes & No & $\begin{array}{l}\text { Neutral/ } \\
\text { not sure }\end{array}$ & $\begin{array}{l}\text { Decline } \\
\text { to answer }\end{array}$ \\
\hline Fragrance-free workplaces & $50.7 \%$ & $16.4 \%$ & $32.1 \%$ & $0.8 \%$ \\
\hline $\begin{array}{l}\text { Fragrance-free } \\
\text { healthcare facilities and } \\
\text { healthcare professionals }\end{array}$ & $64.1 \%$ & $14.0 \%$ & $21.3 \%$ & $0.6 \%$ \\
\hline Airplanes without scented air & $80.2 \%$ & $6.0 \%$ & $13.3 \%$ & $0.5 \%$ \\
\hline Hotels without scented air & $77.7 \%$ & $9.8 \%$ & $12.0 \%$ & $0.5 \%$ \\
\hline
\end{tabular}




\section{University Library}

\section{- M M N E R VA A gateway to Melbourne's research publications}

Minerva Access is the Institutional Repository of The University of Melbourne

Author/s:

Steinemann, A

Title:

Exposures and effects from fragranced consumer products in Sweden

Date:

2018-06-01

Citation:

Steinemann, A. (2018). Exposures and effects from fragranced consumer products in Sweden. AIR QUALITY ATMOSPHERE AND HEALTH, 11 (5), pp.485-491. https:// doi.org/10.1007/s11869-018-0565-5.

Persistent Link:

http://hdl.handle.net/11343/283052 